\title{
A Study on the Usage Status of Daily Consumables for the Visually Challenged and the Utilization of IoT Technology
}

\section{시각장애인을 위한 소모성 생활제품의 사용현황 및 IoT 기술 활용 연구}

Hyeon Jeong $\mathrm{Kim}^{1}$

김현정 1

${ }^{1}$ Professor, Department of industrial Design, SangMyung University, Korea, illusion1014@smu.ac.kr

\begin{abstract}
For the convenience of living for the visually challenged, various technologies and products have been steadily studied from the viewpoint of auxiliary engineering, but most of the developments have revolved around those for outdoor walking and mobility for the visually impaired. In reality, research on technological design for consumable household goods, which are used almost every day by both the disabled and the non-disabled, is quite inadequate. This study thus aims to put forth technical product designs geared toward enhancing convenience of the visually impaired people when it comes to frequently used everyday household items, thus helping them lead an independent life in a more meaningful way. To this effect, this study undertook research on cases, usage status, IoT application designs targeting on the products most frequently used in our daily life. As for the research progress and method, this study first reviews the characteristics and types of each product in 235 cases related to consumable items frequently used in daily life, and investigates and analyzes the process and status of each product by visually challenged people through experiential research and observation surveys. Furthermore, based on the results of product case studies and usage status studies, it proposes an IoT technology-based product information delivery design that can address issues that might occur during the use of each product. In line with case studies and usage status studies, product packaging, and operational aspects of products, this study assesses multiple issues raised when the visually challenged people use household products, and suggests the IoT technology-based application designs that can be conducive to the visually challenged to accurately recognize and more comfortably use.
\end{abstract}

Keywords: Visually Impaired, Consumable Household Goods, Experiential Observational Survey, IoT Technology, Product Information Delivery

요약: 시각장애인의 생활 편의를 위해 보조공학적 측면에서 다양한 기술과 제품들이 꾸준히 연구되어오고 있으나 대부분의 개발 기술과 제품들은 시각장애인의 이동성을 위한 실외 보행 및 이동 편의 기술과 제품들이다. 따라서 장애인과 비장애인 모두 거의 매일 같이 사용하고 있는 소모성 생활제품(용품)에 대한 기술디자인 연구는 매우 부족한 실정이다. 이에 본 연구는 시각장애인의 생활제품 사용 편의를 위한 기술디자인을 목표로, 생활 속에서 사용빈도가 높은 소모성 생활제품을 대상으로 제품 사례연구 및 사용현황연구, 정보전달 어플리케이션 디자인 연구 등을 진행하여, 최종적으로 시각장애인의 생활 자립에 도움을 줄 수 있는 제품사용의 편의기술 디자인을 제안하고자 한다. 연구진행 및 방법으로는 일상생활에서

Received: September 27, 2021; $1^{\text {st }}$ Review Result: November 13, 2021; $2^{\text {nd }}$ Review Result: December 29, 2021 Accepted: January 29, 2022 
먼저 자주 사용하고 있는 소모성 생활제품사례 235건 대상으로 각 제품의 특징과 유형을 검토하고, 대표적인 포장 유형 27종을 대상으로 시각장애인 체험 관찰조사를 진행하여 시각장애인 사용자의 제품 사용과정과 현황, 문제점 등을 조사 검토한다. 그리고 제품사례와

사용현황 연구결과를 기반으로 각 제품의 사용성 문제를 해결할 수 있는 IoT 기술 기반 제품정보전달 디자인을 제안한다. 이상의 생활제품의 사례조사연구와사용현황 연구결과, 소모성 생활제품의 포장 형태와 내용물 유형, 시각장애인의 제품 사용 방법 및 사용상의 다양한 문제점들이 검토되었고, 이러한 문제의 디자인적 해결방안으로 시각장애인의 제품정보인지 및 사용 방법을 도와줄 수 있는 IoT기술 기반 어플리케이션 디자인이 제안되었다.

핵심어: 시각장애인, 소모성 생활제품, 체험관찰조사, IoT기술, 제품정보전달

\section{1. 서론}

보건복지부의 ‘2020년 등록장애인 현황'[1] 자료에 따르면 국내 전체 장애인의 수는 $2,633,026$ 명이며, 이 중에 시각장애인의 수는 약 252,000 명으로 전체 장애인의 $9.6 \%$ 에 해당되며, 전 세계적으로는 약 2억 4000만명으로 그 수는 매년 증가하고 있는 실정이다. 그럼에도 불구하고 시각장애인의 생활 자립에 도움을 줄 수 있는 소모성 생활제품의 사용성 연구는 매우 부족한 상황이다. 최근 보조공학 분야에서 시각장애인을 위한 기술연구가 다수 진행되고 있으나 대부분의 연구주제가 시각장애인의 이동성과 관련한 이동과 보행 환경 및 시설물 등에 관한 연구로 거의 매일 같이 빈도 높게 사용하는 소모성 생활제품에 대한 연구는 매우 부족한 실정이다. 이에 본 연구는 소모성 생활제품을 대상으로 사례연구와 시각장애인 체험의 사용현황연구 등을 진행하여 시각장애인의 자립적 실내생활에 도움을 줄 수 있는 IoT 기술 기반 제품정보전달디자인 방안을 제안하고자 한다. 세부 연구진행 내용으로는 먼저 문헌연구를 통해 시각장애인 대상 생활제품의 안전사고 현황 및 관련 디자인 연구 현황을 검토하고, 두 번째로 사례조사 방법으로 다양한 생활제품사례들을 수집하여 제품의 특성과 유형들을 분류 분석하고, 세 번째로 시각장애인 체험의 관찰조사를 진행하여 시각장애인의 생활제품 사용과정과 문제점들을 단계적으로 검토한다. 그리고 마지막으로 이상의 연구결과에 기반하여 시각장애인의 생활제품 사용과정을 도울 수 IoT기술 기반 디자인 방안을 제안한다.

\section{2. 시각장애인 대상 소모성 생활제품의 안전사고 현황조사}

\section{1 조사목적 및 방법}

시각장애인을 대상으로 소모성 생활제품의 안전사고 현황을 파악하기 위해 소비자원의 생활제품 안전사고 관련 보고서 및 보도자료와 법제처의 생활제품 안전사고 예방을 위한 시행법안 자료, 시각장애인 대상 생활제품 디자인 연구자료 등의 문헌 자료를 대상으로 내용을 검토 정리한다. 


\section{2 조사결과}

2017년 한국소비자원의 '생활화학제품 사용 중 안전사고 지속적으로 발생' 보도자료 [2]에 따르면 다양한 소모성 생활제품들로 인한 안전사고들이 발생하고 있는 것으로 보고되고 있다. 특히 세탁 세정제의 내용물이 눈에 들어가 결막이나 각막을 손상시킨 안전사고 비율 $35.4 \%$, 세정제를 음료수로 오인해 마신 안전사고 비율 $28.3 \%$ 등으로 소모성 생활제품의 안전사고 가능성이 매우 높은 것으로 검토되었다. 그리고 2018년 소비자원의 '생활화학제품 어린이 보호포장 확대 필요' 보도자료[3]에 따르면 생활 안전사고 다발 품목으로 세정제 $34.5 \%$, 방향제 $15.5 \%$, 습기제거제 $14.5 \%$, 합성세제 $9.5 \%$ 등의 순인 것으로 보고하고 있으며, 이런 안전사고에 가장 많이 피해를 보고 있는 대상이 5세 미만 아동(89.5\%)들인 것으로 보고하고 있다.

[표 1]은 세정제 제품의 안전사고 예방을 위한 국내외 어린이 보호포장 적용 현황 자료[3]로 해외 제품과 비교하여 국내 제품의 대부분은 안전사고 예방 디자인이 되어있지 않은 것을 알 수 있다. 생활제품의 안전사고 문제는 어린이를 비롯하여 노인이나 시각장애인 등의 정보전달 취약계층에게서 빈번히 일어날 수 있는 문제들로서 해결방안 마련이 시급하다. 일부 생활제품 생산기업에서는 이러한 문제의 해결방안으로 [그림 1][4]과 같이 유니버설디자인의 일환으로 제품 포장의 점자 정보 표시방안과 점자 스티커 보급방안 등을 제시하고 있다.

[표 1] 세정제 제품의 안전사고 예방을 위한 국내외 포장 적용 실태

[Table 1] Comparison of Domestic and Foreign Child Protection Packaging Application by Type (formulation) of Detergent, etc.

\begin{tabular}{|c|c|c|c|}
\hline 구분 & 한국 & \multicolumn{2}{|c|}{ 해외 } \\
\hline $\begin{array}{l}\text { 세 } \\
\text { 정 } \\
\text { 제 }\end{array}$ & 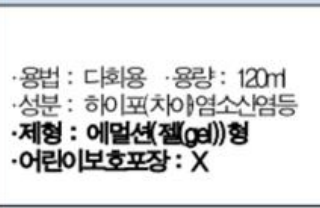 & 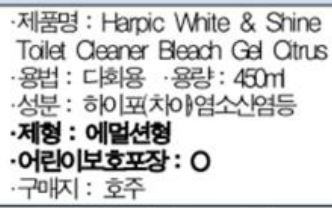 & \\
\hline \multirow{3}{*}{$\begin{array}{l}\text { 세 } \\
\text { 정 } \\
\text { 제 }\end{array}$} & $\begin{array}{l}\text { 용법 : 다화용 용량: } 200 \mathrm{~g} \\
\text { 성분: 하이포차아염소산염 } \\
\text { 수산화나트륨 등 } \\
\text { ·제형: 에멀션형 } \\
\text { ·어린이보호포장 : } \mathrm{X}\end{array}$ & 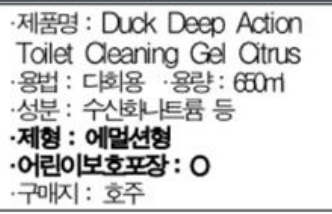 & \\
\hline & 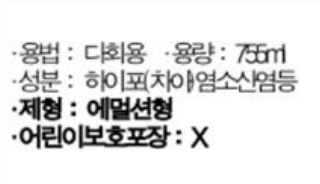 & 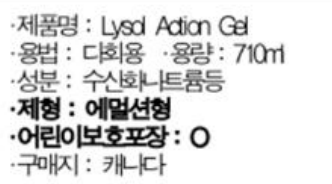 & \\
\hline & $\begin{array}{l}\text { 용법 : 대화용 용량: } 11 \\
\text { 성분 : 하이포차아염소닌염등 } \\
\text { ·제형 : 에멀션형 } \\
\text { ·어린이보호포장 : } \mathrm{X}\end{array}$ & 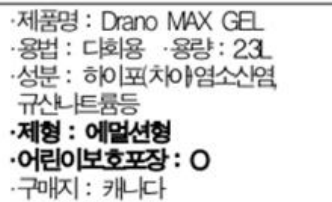 & \\
\hline $\begin{array}{l}\text { 표 } \\
\text { 백 } \\
\text { 제 }\end{array}$ & $\begin{array}{c}\text { ‘세제류' 중 ‘세정제를 제외한 ‘표백제’, } \\
\text { ‘합성세제 등은 모두 } \\
\text { 어린이보호포장 대싱에서 제외 }\end{array}$ & 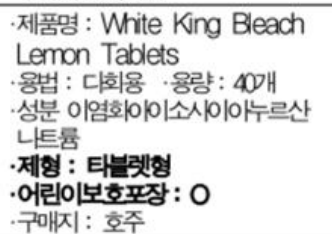 & $\frac{\text { Kning }}{\text { to BLEA }}$ \\
\hline
\end{tabular}




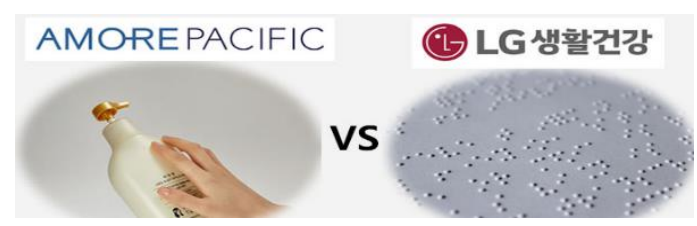

[그림 1] 아모레퍼시픽에서의 유니버설디자인과 LG생활건강의 점자스티커

[Fig. 1] Amorepacific's Universal Design and LG Household \& Health Care's Braille Sticke

그 밖에도 우리나라 환경부는 이와 같은 문제의 예방조치로 2021년 7월 '안전확인대상 생활화학제품 지정 및 안전·표시기준' 시행 법안을 개정 발행, 해당 법안 별표 6안전확인대상 생활화학제품의 표시방법, 1.표시일반사항 라항[5]에 시장장애인을 포함한 정보취약계층을 위한 생활화학제품 표시방법에 대해 다음과 같은 내용들을 제시하고 있다.

라. 표시가 소비자에게 정확하고 이해하기 쉬운 제품의 정보를 전달할 수 있도록 다음 아래의 표시방법을 권장한다.

1)시각장애인의 올바른 제품사용을 위하여 품목, 제품명, 안전기준, 적합확인신고번호 등의 표시사항을 점자 등의 방법으로 병행하여 표시

2)표시사항을 시각적으로 잘보이고 쉽게 이해될 수 있도록 사용상의 주의사항, 응급조치, 등의 표시사항을 그림기호로 표시

3)제품 내 별도 첨부문서가 동봉된 경우 “동봉된 첨부문서를 확인하시오” 등의 안내문 표시

4)어린이의 삼킴 및 중독사고 예방을 위하여 살균소독제품, 구제제품, 보존제품에 식품 관련 도안 및 만화 캐릭터 표시 자제

위 시행 법안 내용을 살펴보면 '점자 표시', '시각적으로 잘 보이게', '그림기호 표시'“첨부문서', ‘안내문 표시' 등의 법안 세부내용들을 확인할 수 있으며, 이러한 내용은 시각장애인의 신체적 학습적 상황들을 $100 \%$ 반영한 내용이라고 보기 어렵다. 2008년 ‘장애인차별금지법'[6] 이후 2021년 최근 개정안이 시행되어 사회 전반에서 장애인의 보편적 편의에 관심을 기울이기 시작하여 최근 장애인 복지정책은‘장애인을 특별히 배려'하는 것에서 '장애인과 모든 활동을 공유'하는 것으로 인식이 바뀌고 있으며, 다양한 생활 환경적 측면에서 장애인의 사용 편의를 개선고자 하는 정책, 기술, 디자인 등의 연구를 진행하고 있다. [표 2]은 한국 비자원의 시각장애인 안전사고 관련 최근 보고서 및 보도자료를 검토한 것으로서 대부분의 내용이 실외 이동과 보행 환경에 따른 시설물의 문제 내용으로 소모성 생활제품의 안전사고 검토 내용이 부족한 것으로 파악되었다. [표 3][7-9]는 국내 시각장애인 대상 생활제품 관련 연구로 연구내용 대부분이 유니버설디자인 원칙에 기반한 내용으로 제품 포장디자인의 점자표기 혹은 시각적 표기 방안 등과 관련한 연구임이 검토되었다. 2017년 보건복지부 장애인실태조사 보고서[10] 자료에 따르면 전체 시각장애인(28만 7,000여 명)의 $92.4 \%$ 는 후천적으로 시각장애인으로 문자 체계와 비장애인의 삶에 익숙해진 후천적 시각장애인들에게 점자 습득은 매우 어려운 학습 과정으로 점자 문맹률은 전체 시각장애인의 $86 \%$ 에 해당하는 것으로 
보고하고 있다.

그럼에도 불구하고 [표 2]의 국내 시각장애인 대상 연구내용들은 여전히 점자표기, 시각적 표기 등과 관련한 연구주제에서 벗어나지 못하고 있음을 알 수 있다. [표 4][1113]은 시각장애인 대상 생활제품 해외 연구자료로서 시각장애인의 대상 제품 및 포장디자인 연구들이 다각적 관점에서 진행되고 있으며, 시각장애인 소비자의 니즈를 검토하여 제품디자인 개발에 적극 반영하고 있음을 알 수 있다.

[표 2] 한국소비자원의 시각자애인 관련 안전문제 보도자료

[Table 2] Consumer Agency, Press Release related to the Safety of the Visually Impaired

\begin{tabular}{|c|c|c|}
\hline 연도 & 문서유형 & 제목 \\
\hline 2021.01.21 & 보도자료 & 건물 주차장 차량 진출입로, 시각장애인 사고 위험 높아 \\
\hline 2021.03 .10 & $\begin{array}{l}\text { 안전조사 } \\
\text { 보고서 }\end{array}$ & $\begin{array}{c}\text { 시각장애인 보행 안전실태조사(건물 주차장 출입구 인접 보도를 } \\
\text { 중심으로) }\end{array}$ \\
\hline 2018.12 .18 & 보도자료 & 지하철, 장애인 이용 시 안전사고 위험 높아 \\
\hline 2017.09.07 & 보도자료 & 육교 승강기, 관리감독 안되고 안전성도 문제 있어 \\
\hline
\end{tabular}

[표 3] 국내 시각장애인 대상 생활제품 디자인 연구 현황

[Table 3] Current Status of Research on Design of Household Products for the Visually Impaired in Korea

\begin{tabular}{|c|c|c|c|}
\hline 연도 & 연구자 & 제목 & 내용 \\
\hline 2015 & 이경수 & $\begin{array}{c}\text { 유니버설 디자인 적용을 } \\
\text { 위한 생활용품 } \\
\text { 패키지디자인 연구-샴푸, } \\
\text { 바디워시를 중심으로- }\end{array}$ & $\begin{array}{c}\text { 유니버설디자인 6원칙에 입각한 생활제품 } \\
\text { 표시정보의 시각디자인적 방안을 연구한 내용 }\end{array}$ \\
\hline \multirow{2}{*}{2010} & 시각장애인을 위한 \\
신현호, 강재도 & $\begin{array}{c}\text { 포장구조의 촉각식별마크 } \\
\text { 삽입에 관한 연구 }\end{array}$ & $\begin{array}{c}\text { 유니버설 디자인 측면에서 시각장애인들이 } \\
\text { 접근가능하고 각종 식품이나 기타 제품들의 } \\
\text { 오남용을 막을 수 있는 패키지디자인에 관한 } \\
\text { 연구로 점자표기, 점자·음성 변환용 코드 내용 }\end{array}$ \\
\hline $\begin{array}{c}\text { 김유철, 루이스, } \\
\text { 이젼, 최용준, } \\
\text { 조준동 }\end{array}$ & $\begin{array}{c}\text { 시각장애인을 위한 스마트 } \\
\text { 약 포지 제작 및 } \\
\text { 어플리케이년 개발 }\end{array}$ & $\begin{array}{c}\text { 약을 복용하는데 불편함을 격고 있는 시각장애인을 } \\
\text { 위한 스마트 약 포지 제작 및 어플리케이션 개발 } \\
\text { 내용 }\end{array}$ \\
\hline
\end{tabular}

[표 4] 해외 시각장애인 대상 생활제품 디자인 연구 현황

[Table 4] Current Status of Research on Design of Household Products for the Visually Impaired in Overseas

\begin{tabular}{|c|c|c|c|}
\hline 연도 & 연구자 & 제목 & 내용 \\
\hline $\begin{array}{c}2018 . \\
11\end{array}$ & $\begin{array}{l}\text { Monika Rastovac, } \\
\text { Jurica Dolić, } \\
\text { Jesenka } \\
\text { Pibernik ,Lidija } \\
\text { Mandić }\end{array}$ & $\begin{array}{l}\text { User-Centered Approach to } \\
\text { Product Design for People with } \\
\text { Visual Impairments }\end{array}$ & $\begin{array}{c}\text { 사용자 중심 디자인 프로세스를 응용하여 } \\
\text { 시각장애가 있는 사람들에게 적합한 제품 및 포장 } \\
\text { 디자인을 개발하는 내용의 연구 }\end{array}$ \\
\hline
\end{tabular}




\begin{tabular}{|c|c|c|c|}
\hline \multirow{2}{2019.}{} & $\begin{array}{c}\text { Maria Lilian De } \\
\text { Araújo Barbosa, } \\
\text { Gisele Yumi Arabori } \\
\text { Ribeiro, } \\
\text { Isabel Gebauer } \\
\text { Soares } \\
\text { Maria Lucia } \\
\text { Okimoto }\end{array}$ & $\begin{array}{c}\text { Accessible Packaging: A Study } \\
\text { for Inclusive Models for Visual } \\
\text { Impairment People }\end{array}$ & $\begin{array}{c}\text { 시각장애인 대상 제품 포장의 정보 취급, 개봉 및 } \\
\text { 식별 응이하게 하기 위한 사용자 니즈 연구 및 } \\
\text { 포장디자인 제안 연구 }\end{array}$ \\
\hline 2020. & Jamie Milar-Bentia & $\begin{array}{c}\text { Accessible Packaging Design } \\
\text { in the Beauty Industry }\end{array}$ & $\begin{array}{c}\text { 뷰티산업제품의 패키징 디자인과 관련하여 장애가 } \\
\text { 있는 사람들이 제품에 보다 쉽게 접근할 수 있도록 } \\
\text { 하는 디자인 연구 }\end{array}$ \\
\hline
\end{tabular}

\section{3. 소모성 생활제품의 사례조사 및 시각장애인 체험 관찰조사}

\section{1 조사목적}

우리나라는 2017년 5월부터 점자법이 시행되어, 공직선거법, 약사법, 여권법, 저작권법, 주민소환법, 자전거법, 화장품법, 우편법 등 점자 관련 법률만 14 가지에 달하며, 최근 국내 몇몇 제약회사를 포함하여 유명 생활제품 브랜드 기업에서는 제품 용기나 포장에 점자 정보표기를 시행하고 있다. 본 연구의 사전 조사로서 실제 시각장애인들 대상으로 무작위로 의약품과 생활용품 포장의 점자 정보의 내용을 조사 확인해 본 결과, 점자표기 오류 및 부정확한 제품정보표기로 실질적 제품 파악에 큰 도움을 주지 못한 것으로 파악되었다. 이에 본 연구에서는 소모성 생활제품의 사례연구를 통해 제품의 내용물과 제품 포장 특성 등을 검토하고, 시각장애인 체험-관찰조사를 통해 제품 유형별 사용성 상황들을 검토해 보고자 한다.

\section{2 조사방법}

연구방법으로는 일상생활에서 주로 사용하고 있는 소모성 생활제품(생활화학제품) 들을 구입하여 각 제품의 내용물 및 포장디자인의 특징들 검토하고, 비장애인 참가자의 시각장애인 체험상태(안대를 끼고 시각을 차단한 상태)에서의 제품 사용과정 관찰조사를 통해 각 제품의 사용상의 문제점들을 검토, 분석한다. 1)먼저 사례연구에 사용된 소모성 생활제품은 총 235 건으로, 시각장애인 대상 사전조사를 통해 제품의 외형과 내용물의 구별이 어려운 주방용 제품 26건, 욕실용 제품 80건, 세탁용 제품 32건, 화장품 97 건 이 사례연구에 사용된다. 2)그리고 시각장애인 체험-관찰조사 재료로는 사례연구결과에 기초하여 대표적으로 선정된 총 27종(제품의 용도가 다른 펌프형 8 종, 분사형 3 종, 뚜껑형-전체오픈, 일부오픈 형 6종, 뚜껑 튜브형 3종, 병타입 4종, 돌출뚜껑 1종, 반부착 뚜껑 1 종, 튜브형 1 종)의 제품이 사용된다. 시각장애인 체험 참가자는 시각 차단용 안대를 한 상태에서 조사자로부터 주어진 제품의 용도 설명을 들은 후, 행위과제로 해당 제품을 자연스럽고 편하게 용도에 맞게 사용하는 행위과제가 주어진다. 그리고 조사자는 각 참가자 제품의 사용상황을 관찰영상으로 기록하고 영상 데이터를 기반으로 제품별 사용단계 및 사용 시간, 사용행위 특성, 사용상의 문제점 등을 분석한다. 


\section{3 조사결과}

\section{1) 생활용품 사례조사 결과}

먼저 235건(주방용 제품 26건, 욕실용 제품 80건, 세탁용 제품 32건, 화장품 97건)의 소모성 생활제품의 사례들을 대상으로 제품의 내용물과 포장디자인 특징을 유형별로 분류 정리한 결과, [표 5]와 같이 주방용 제품은 크게 용도에 따라 식기용, 과일용, 청소용 세제로 분류되었으며, 욕실용 제품은 헤어(샴푸,린스), 세안(세안제, 클린싱), 구강(치약, 구강청결제), 바디(바디샴푸, 입욕제, 바디스크럽), 청소(욕실, 변기) 제품들로 분류되었고, 세탁용 제품은 일반세탁용, 특수(기능성)세탁용, 섬유유연제, 표백제 등으로, 화장품은 기초(스킨, 로션), 기능성(영양, 수분, 미백, 주름, 썬 크림), 메이컵 (베이스, 파운데이션, 비비), 바디(바디로션, 바디크림, 풋바디, 핸드크림, 핸드로션) 제품들로 분류되었다. 그리고 각 제품들을 포장디자인의 특성에 따라 분류한 결과 직육면체형, 일반 병 모양형(뚜껑이 있는 병), 펌프형, 분사형, 튜브형, 스포이드형, 리필형(용기, 봉지) 등으로 분류되었으며 제품의 내용물 유형으로는 가루, 액상, 젤, 크림, 고체, 페이퍼 등의 유형으로 분류되었다. 그리고 이러한 각 제품의 유형 검토 결과는 다음의 어플리케이션 구축의 기반자료로 활용한다.

[표 5] 생활제품의 용도별 유형별 사례 분석

[Table 5] Case Analysis of Types, Uses, and Packaging Types of Household Goods

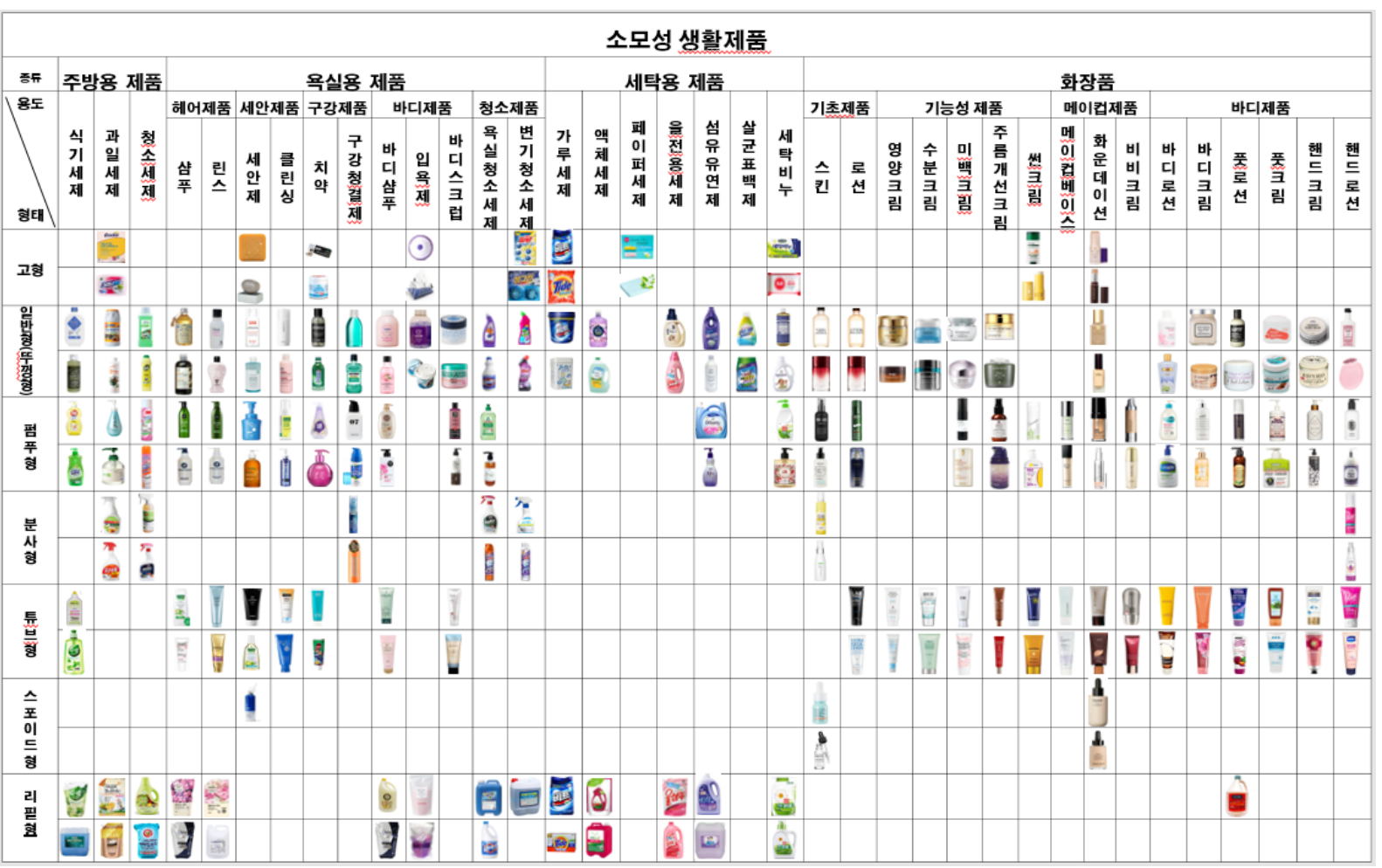

2) 시각장애인 체험 관찰조사 결과

[표 6]은 시각장애인 체험 관찰조사를 통한 생활제품의 사용과정을 정리한 결과로 제품 유형별 사용시간과 사용상의 오류행위 등이 검토되었고, 사용시간이 가장 긴 제품으로 '분사형 제품'과 '뚜껑의 직경 큰 제품', 그리고 '튜브형 제품' 순으로 사용시간이 
긴 것으로 조사되었으며, 사용시간이 가장 짧은 제품으로는 펌프형과 일반 병타입 제품인 것으로 파악되었다. 그리고 이러한 결과를 통해 사용시간이 짧은 제품은 시각장애가 있는 사용자에게 있어 비교적 사용이 편리한 유형의 제품이며, 사용시간이 긴 제품은 사용이 불편한 제품인 것으로 검토되었다. 그 밖에도 시각장애인 체험자가 제품의 용도를 사전 인지한 상태임에도 불구하고 사용행위 오류가 발생하는 제품으로는 제품의 사용 용량을 사용자 본인이 직접 조절 사용해야 하는 액체형 제품과 반부착형 용기의 제품인 것으로 검토되었다. 이러한 시각장애인 체험 조사결과를 바탕으로 생활제품의 종류 및 사용방법, 사용단계, 내용물의 사용 용량 등을 유형화하여 시각장애인 소비자에게 보다 쉽게 제품의 사용정보를 전달할 수 있는 IoT 기술 기반 제품정보전달 디자인의 필요성이 고찰 검토되었다.

[표 6] 시각장애인 체험을 통한 생활용품 사용과정 관찰조사 결과

[Table 6] Results of Observational Survey on the Use of Household Goods through the Experience of the Visually Impaired

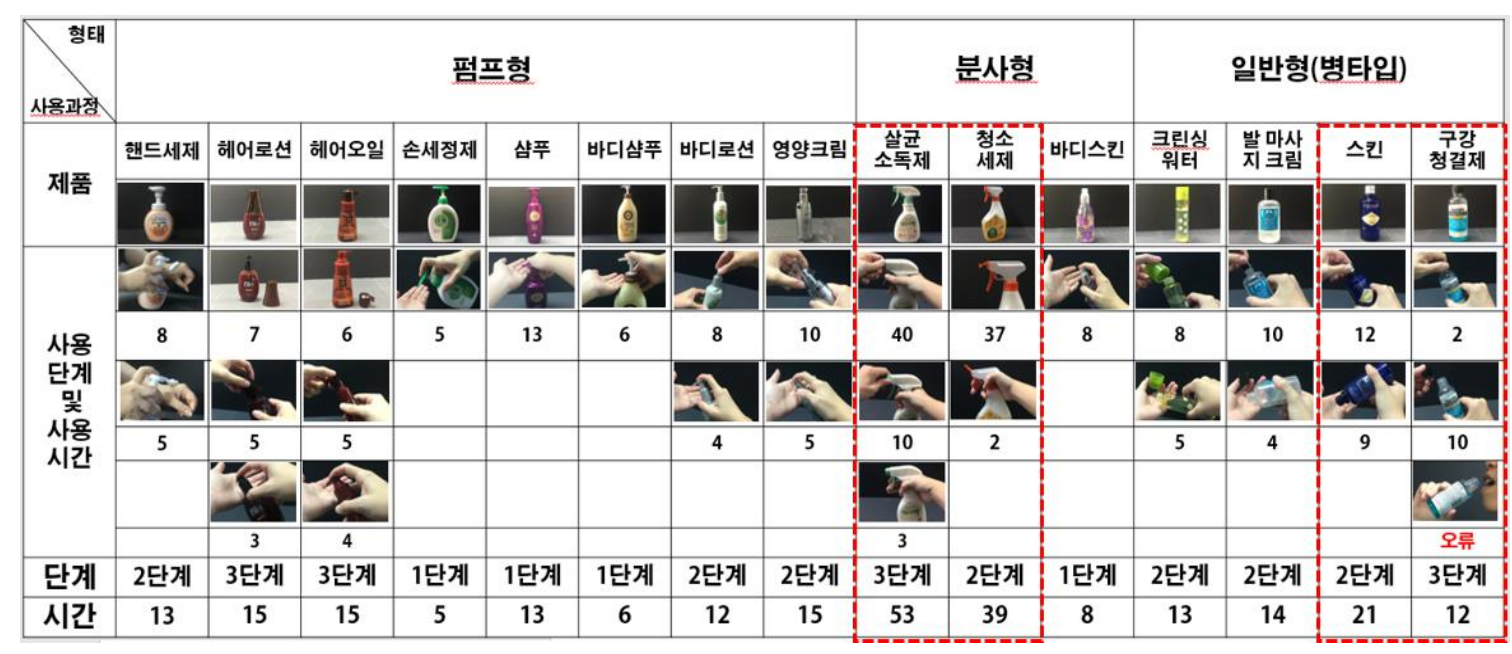

\begin{tabular}{|c|c|c|c|c|c|c|c|c|c|c|c|}
\hline \multirow{2}{*}{$\begin{array}{l}\text { 반부 } \\
\text { 착형 } \\
\text { 뚜껑 } \\
\text { 바디샴푸 }\end{array}$} & \multicolumn{6}{|c|}{ 뚜껑형 } & \multicolumn{3}{|c|}{ 뚜껑 튜브형 } & \multirow{2}{*}{ 튜브형 } & \multirow{2}{*}{$\begin{array}{l}\text { 도출 } \\
\text { 뚜껑 } \\
\text { 올림형 } \\
\text { 주방세제 }\end{array}$} \\
\hline & $\begin{array}{l}\text { 크ㄹㅣㅣ싱 } \\
\text { 워터 }\end{array}$ & 영양크림 & 수분크림 & 스킨 & 바디샴푸 & 샴푸 & 헤어젤 & 린스 & 영양크림 & & \\
\hline & & & & & & & & & & & $t$ \\
\hline $\begin{array}{c}13 \\
\text { (오류) }\end{array}$ & 6 & 12 & 23 & 10 & 9 & 7 & 7 & 10 & 8 & 12 & 8 \\
\hline 5 & 6 & 7 & 5 & 6 & 6 & 8 & 7 & 19 & 4 & 30 & 5 \\
\hline & & 2 & 2 & & & & & & & & \\
\hline 2단계 & 2단계 & 3단계 & 3단계 & 2단계 & 2단계 & 2단계 & 2단계 & 2단계 & 2단계 & 2단계 & 2단계 \\
\hline 18 & 12 & 21 & 30 & 16 & 15 & 15 & 14 & 29 & 12 & 42 & 13 \\
\hline
\end{tabular}

\section{4. 소모성 생활제품의 정보전달기술 디자인}

\section{1 기술디자인 목적}

제 3장의 생활제품의 사례연구와 시각장애인 체험 관찰조사 연구를 통해 생활제품의 
용도, 유형, 포장특성, 사용방법, 사용시간 등이 자세하게 검토되었다. 이에 본 연구에서는 이상의 연구결과를 바탕으로 실제 시각장애인 소비자가 직접 소모성 생활제품을 사용하게 될 경우, 제품의 용도와 포장특성, 사용방법, 사용량 등의 세부 정보를 쉽게 이해하고 직관적으로 사용할 수 있도록 하는 '기술디자인'을 제안해보고자 한다. 본 연구에서의 기술디자인이란 현재 개발되어 있는 기술의 원리나 기술자원 응용하여 제품 사용상의 문제를 해결할 수 있는 방안으로 제안하는 것을 의미한다.

\section{2 기술디자인 방법}

기술디자인 방법으로 IoT(Internet of Things, 사물인터넷)기술 원리와 [그림 2]와 같이 NFC 근거리 무선 통신기술[14], NFC Tag, 스마프폰에 내장된 기술, 제품정보 입력과 해석(출력) 어플리케이션 등이 기술디자인을 위한 재료로 활용된다. NFC 기술은 근거리 무선 통신을 뜻하는 기술로 두 대 이상의 단말기를 $10 \mathrm{~cm}$ 이내로 접근시켜 양방향 데이터를 송수신하는 기술로서 $\mathrm{NFC}$ 는 $13.56 \mathrm{MHz}$ 의 주파수 대역을 사용하며, 단말기 간의 빠른 양방향 통신이 가능한 전자태그(RFID) 기술의 일종이다. NFC는 비접촉 근거리 무선 통신 기술임에도 불구하고 암호화 기술이 적용되어 무선통신 중에도 정보가 외부로 유출되지 않는 장점이 있다. 그리고 이러한 $\mathrm{NFC}$ 기술은 현재 스마트폰에 내장되어 있는 음성기술과 연동하여 시각장애인들을 위한 기술로 활용하기에 적합한 기술이다.

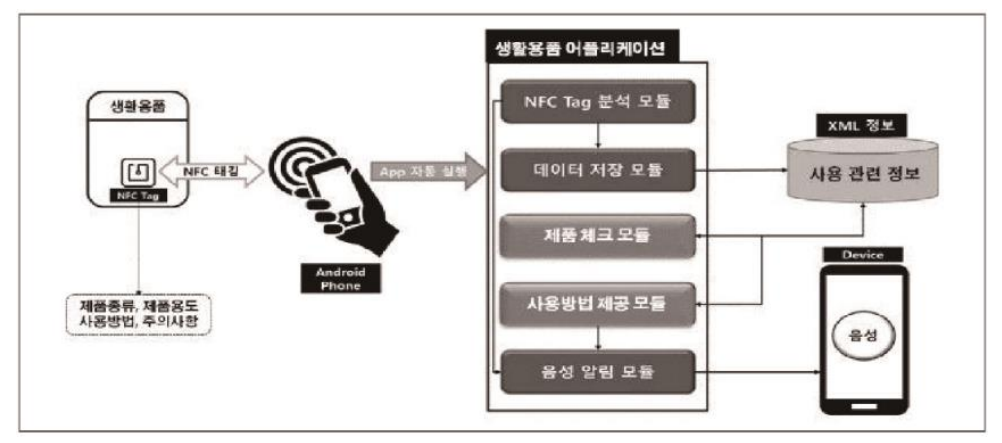

[그림 2] NFC Tag를 활용한 기술 개념도

[Fig. 2] Technical Concept Diagram Using NFC Tag

\section{3 기술디자인 제안}

IoT 기술 원리와 NFC 기술, NFC Tag, 스마트폰 음성기술, 스마트폰 사용 어플리케이션 디자인을 통해 [그림 3]과 같이 시각장애인대상 제품정보전달 기술디자인을 제안, 시각장애인이 격는 제품 사용상의 문제(제품의 종류, 용도 사용방법, 사용용량 인지 등의 문제)해결방안을 제시하였다. 사전에 소모성 생활제품의 종류와 유형, 사용방법, 사용용량 등의 정보를 입력용 Writer 어플리케이션를 통해 입력하고, 제품 사용 시 관련 정보를 음성정보로 제공받을 수 있는 출력용 Reader 어플리케이션을 개발하고 각각의 어플리케이션 UI(User Interface)를 디자인하여 시각장애인 누구나가 본인의 스마트폰으로 구동할 수 있도록 기술디자인을 완성한다. 어플리케이션 이용 방법에 있어서는 시각장애인 소비자가 생활제품에 본인의 스마트폰을 가까이 대면 스마트 폰 내의 Reader 어플리케이션이 작동하여, 음성정보로 해당 제품의 종류와 용도, 사용방법, 사용량 
등을 단계별로 알려 주어 시각장애인 소비자 스스로가 제품을 인식하고 사용할 수 있도록 한다.

본 연구에서 제안하는 정보전달 어플리케이션 디자인은 기존의 제품에 부착하는 점자 스티커의 점자 인식 오류와 문맹률의 문제를 해결할 수 있으며, 또한 기존의 ‘보이스아이'와 ‘비마이아이' 기술과 같이 상품의 바코드를 정확히 스캔하거나 스마트폰 카메라를 통해 상품을 정확히 인식시켜야 하는 사용상의 시각적 문제들을 해결할 수 있는 장점이 있다. 본 연구에서 제안하는 기술디자인은 시각적 인식 장치 없이 사물인터넷의 근거리통신기술(NFC 기술)을 활용하여 시각장애인 소비자에게 보다 적합한 사용과정으로 생활제품의 정확한 정보와 적절한 사용방법을 제공할 수 있다는 차별적 특성이 있다.

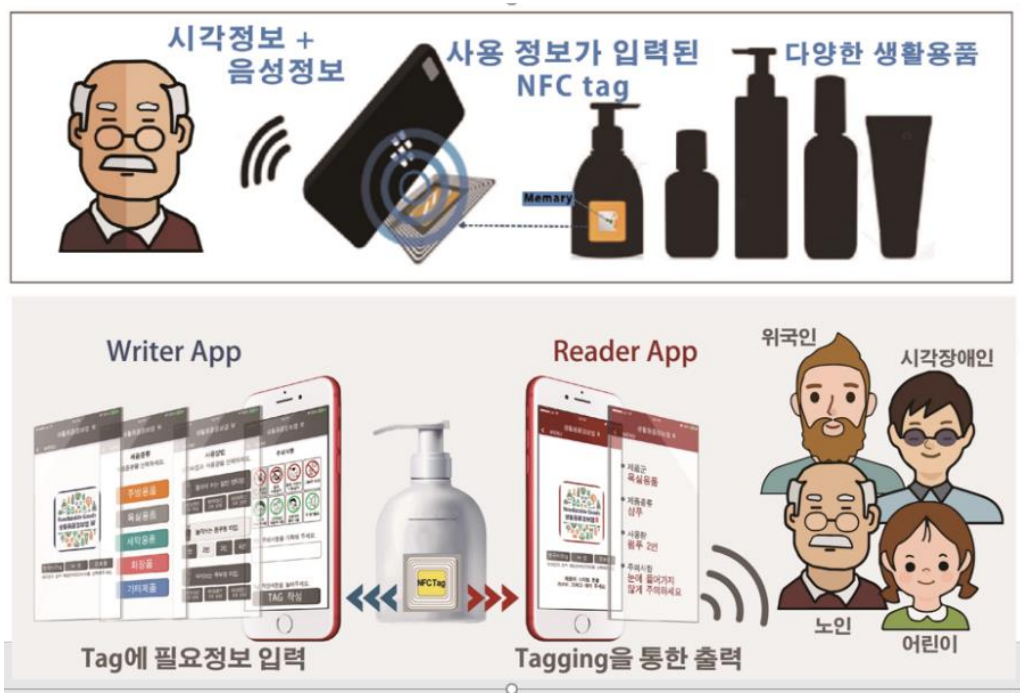

[그림 3] 시각장애인을 위한 생활제품 어플리케이션 디자인

[Fig. 3] Household Goods Application Design for the Visually Impaired

\section{5. 결론}

최근 다양한 IoT 기술들이 쏟아져나오고 있으며 시각장애인의 실외 이동성을 돕는 상황인지 보조기술로 보행자의 길 안내에 자주 사용되고 있다. 그러나 실제 시각장애인이 하루 중 가장 많이 거주, 활동하는 공간은 본인의 자택이며 그들 스스로 자립적 생활을 영위하는데는 많은 어려움이 있다. 이 점에서 본 연구성과는 시각장애인 생활 자립을 위한 제품정보전달 기술디자인으로 향후 시각장애인 소비자뿐만 아니라 제품의 사용 관련 정보들을 충분히 인지하고 있지 못한 노인, 외국인, 어린이 등의 정보취약계층을 위한 기술디자인 연구로 확대해 나갈 수 있으리라 생각한다. 단 본 연구의 실용화를 위해서는 시각장애인 소비자를 대상으로 한 어플리케이션 검증 연구가 필요할 것으로 사료되며, 이에 연구자는 후속 연구로 소모성 생활제품의 정보전달 어플리케이션을 제작, 다수의 시각장애인 소비자를 대상으로 실제 어플리케이션의 사용성 및 정보전달 UI 검증 연구를 진행, 연구성과의 실용화 방안을 모색해 나아갈 계획이다.

\section{6. 감사의 글}

이 논문은 2020년도 상명대학교 교내연구비 지원으로 수행되었음. 


\section{References}

[1] Seonyoung Lee, Youngmi Kim, 2020 Domestic Disabled Person Registration Status, Disabled Persons Policy Division, Ministry of Health and Welfare, p.4, (2021), http:/www.mohw.go.kr/upload/viewer/skin/doc.html?fn= 1618793818099_20210419095658.pdf\&rs=/upload/viewer/result/202202/

[2] Nanjoo Choi, Jin sook Lee, Accidents continue to occur while using household chemical products-Follow the guidelines for use to prevent safety accidents, Korea Consumer Agency, pp.1-8, (2017), https://www.kca.go.kr/home/synapviewer.do?menukey $=4002 \&$ fno $=10014890 \&$ bid $=00000013 \&$ did $=1002030664$

[3] Jisook Yan, Safety Monitoring Bureau, Investigation of the safety status of child protective packaging for household chemical products, Korea Consumer Agency, pp.31-32, (2017), https://www.kca.go.kr/smartconsumer/synapviewer. do? menukey $=7301 \&$ mode $=$ view $\&$ no $=1002617737 \&$ bid $=00000146 \&$ did $=1002617737 \&$ fno $=10021477$

[4] https://www.thebk.co.kr/news/articleView.html?idxno=188708, Oct 25 (2019)

[5] Act on Prohibition of Discrimination against Persons with Disabilities and Remedy of Rights, Act No.17792, Ministry of Health and Welfare, (2021), https://www.law.go.kr/lsInfoP.do?lsiSeq=195377\#0000

[6] Laws Against Discrimination against Persons with Disabilities, Act No.14839, Ministry of Health and Welfare, (2021), https://www.law.go.kr/lsInfoP.do?1siSeq=195377\#J10:0

[7] Kyungsoo Lee, Living Package Design Study for Universal Design Application - Focusing on the Shampoo and Body Wash, Journal of Cultural Product \& Design, (2015), No.41, pp.31-47, UCI: G704-SER000008995.2015..41.010

[8] Hyunho Shin, Jaedo Kang, A Study on the setting with Recognize Mark on the package containers for a person who is visually impaired, Journal of Korean Society of Communication Design, (2010), Vol.13, No.2, pp.115-124, UCI: G704SER000008956.2010.13.2.015

[9] Yu Cheol Kim, Luis Arturo Cavazos Quero, Jing Yang, Dong He, Ji Yeon Lee, Yong June Choi, Jun Dong Cho, Accessible Pharmaceutical Packaging andInformation System for the Visually Impaired, Proceeding of HCI Korea 2017, The HCI Society of Korea, The HCI Society of Korea, pp.519-521, (2017), http://www.dbpia.co.kr/journal/articleDetail?nodeId=NODE07122396

[10] Seonghee Kim, Yeonhee Lee, Wookchan Oh, Joohee Hwang, Miae Oh, Minkyung Lee, Nanhee Lee, Daeun Oh, Dongwook Kang, Gwonjin Kwon, HyeKyung Oh, Sangyong Yoon, Sunwoo,Lee, 2017 Survey on the Disabled, Ministry of Health and Welfare, pp.156-162, (2017), Feb 8-10, Gangwon, Korea, http://www.mohw.go.kr/react/jb/sjb030301vw.jsp?PAR_MENU_ID=03\&MENU_ID=032901\&CONT_SEQ=345972

[11] Monika Rastovac, Jurica Dolić, Jesenka Pibernik, Lidija Mandić, User-Centered Approch to Product Design for People with Visual Impairments, Proceedings - 9th International Symposium on Graphic Engineering and Design GRID 2018, University of Novi Sad, Faculty of Technical Sciences, Department of Graphic Engineering and Design, pp.267-273, (2018), November 8-10, Novi Sad, Serbia, DOI: https://doi.org/10.24867/GRID-2018-p33

[12] Maria Lilian De Araújo Barbosa, Gisele Yumi Arabori Ribeiro, Isabel Gebauer Soares, Maria Lucia Okimoto, Accessible Packaging: A Study for Inclusive Models for Visual Impairment People, Advances in Ergonomics in Design, pp.282-292, (2019)

[13] Jamie Milar-Bentia, Accessible Packaging Design in the Beauty Industry, Ryerson University Graphic Communications Management, GCM Virtual Thesis Expo2020, pp.1-27, (2020), https://www.ryerson.ca/content/dam/gcm/images/Community/Thesis/2020/MilarBentia-Beauty.pdf

[14] Jeonghwan Lee, NFC(Near Field Communication), Korea Internet \& Security Agency, pp.1-6, (2013) 